\title{
Solid Lipid Microparticles Loaded Hydrogel Formulation for Transdermal Delivery of Glucosamine Sulphate
}

\author{
Sundareswara Kumar Chellaswamy ${ }^{1}$, Satheesh Babu Natrajan² \\ 1,2 Department of Pharmaceutics, Lincoln University College, Malaysia.
}

\section{ABSTRACT}

\section{BACKGROUND}

Osteoarthritis is a common, age-related, chronic and slowly progressive joint disorder which ultimately leads to joint failure. To achieve sustained release drug delivery and ease of administration, the present study was carried out to formulate a glucosamine solid lipid microparticle-based hydrogel.

\section{METHODS}

20 batches of glucosamine solid lipid microparticle were prepared by melt dispersion technique. They were then evaluated with regard to various parameters such as physical appearance, $\mathrm{pH}$ analysis, spreadability, viscosity, drug content, in vitro drug release and accelerated stability studies. Then the glucosamine solid lipid microparticle-based hydrogel was compared with the glucosamine loaded hydrogel.

\section{RESULTS}

Of these batches, batches 18, 19 and 20 of increasing homogenizing speed of 1000 , 1500 and $2000 \mathrm{rpm}$ were found be efficient but the batch 18 showed better encapsulation efficiency. Batch 18 showed particle size of $86 \pm 5 \mu \mathrm{m}$, encapsulation efficiency of $81.74 \pm 4.5$ and the zeta potential value of $-29 \pm 1$. So, batch 18 was found to be the optimised formulation which was further taken for incorporating the Carbopol. The efficient encapsulated glucosamine solid lipid microparticle-based hydrogel was formulated. There were no significant changes in physicochemical properties on stability studies.

\section{CONCLUSIONS}

Glucosamine solid lipid microparticle-based hydrogel had good particle size, high encapsulation efficiency and high zeta potential value and showed high percentage drug release which was better than the glucosamine loaded hydrogel.

\section{KEY WORDS}

Glucosamine Solid Lipid Microparticle Based Hydrogel, Osteoarthritis, Encapsulation Efficiency, Zeta Potential, Melt Dispersion Technique
Corresponding Author: Sundareswara Kumar Chellaswamy, Research Scholar, Department of Pharmaceutics, Lincoln University College, Petaling Jaya, Selangor, Kuala Lumpur - 47031, Malaysia. E-mail: sundaresh.chella@gmail.com

DOI: $10.14260 /$ jemds/2021/220

How to Cite This Article: Chellaswamy SK, Natrajan SB. Solid lipid microparticles loaded hydrogel formulation for transdermal delivery of glucosamine sulphate. J Evolution Med Dent Sci 2021;10(14):1030-1034, DOI: $10.14260 /$ jemds $/ 2021 / 220$

Submission 10-10-2020,

Peer Review 05-02-2021,

Acceptance 11-02-2021,

Published 05-04-2021.

Copyright (C) 2021 Sundareswara Kumar Chellaswamy et al. This is an open access article distributed under Creative Commons Attribution License [Attribution 4.0 International (CC BY 4.0)] 


\section{BACKGROUND}

In India, osteoarthritis scores top five chronic diseases; osteoarthritis affect about $4-6 \%$ of adult population. ${ }^{1}$ Osteoarthritis is also known as degenerative joint disease or degenerative arthritis or OA or wear-and-tear-arthritis. It is a common joint disorder affecting millions of people in developed countries. Osteoarthritis prevalence is remarkably higher in women than in men and increases with age. Statistics indicate that India records more than 10 million cases of osteoarthritis on an annual basis. The most common symptom of osteoarthritis is pain in the affected joint (s) after repetitive use. Other osteoarthritis symptoms and signs include swollen joints, joint stiffness, joint creaking and loss of range of motion. The currently available treatments of osteoarthritis tend to be focused on symptomatic relief, rather than curative processes, through pain alleviation. (Example: non-steroidal antiinflammatory agents, intra-articular hyaluronic acid injection). Glucosamine is a type of glycosaminoglycan, an amino saccharide which is produced in highest concentration in joints, and the preferred substrate for the biosynthesis of proteoglycans, such as aggrecans, which maintain cartilage integrity and function. Glucosamine reduces proteoglycan loss, delays cartilage degeneration and joint-space narrowing and improves osteoarthritic pain in osteoarthritis animals and patients. ${ }^{2}$

Solid lipid microparticles (SLMs) is a potential drug carrier systems and as alternative material to polymer. They can be considered as physiologically compatible, physiochemical stable and allowing a large-scale production at a relatively low production cost than liposomes. These micrometer-sized particles consist of a solid fat core based on naturally occurring lipids and stabilised by surfactant molecules. ${ }^{3}$ The solid matrix protects loaded labile substances against degradation, and it offers the possibility of controlled drug release and drug targeting. It offers the advantage of allowing the hydrophilic and hydrophobic drugs to be incorporated. The most significant challenge that persists with drug delivery for $\mathrm{OA}$ is a lack of vasculature within synovial joints; this is a significant barrier to bio distribution of systemically delivered therapies to the target site. Another challenge is rapid clearance of locally delivered therapeutics due to synovial fluid exchange. The presence of synovial fluid makes the delivery of hydrophobic drugs difficult, as they lack the ability to disperse within the joint.

However, hydrophilic therapeutics such as proteins are cleared from the joint via pressure gradients that cause flow of the synovial fluid. These barriers are cleared by the solid lipid microparticle route of drug delivery. Glucosamine is a potential candidate for the treatment of osteoarthritis. The glucosamine solid lipid microparticle loaded hydrogel offers greater advantage over glucosamine loaded hydrogel since its small size not only makes them needle-injectable, but also leads to large surface area for bio conjugation, facile natural clearance and can enhance penetration through tissue barriers. ${ }^{4}$ In the present study, the glucosamine solid lipid microparticle loaded hydrogel (GS-SLM) showed the optimised formulation batch 18 showed good particle size and high encapsulation efficiency than the glucosamine loaded hydrogel.

Various parameters such as the physical appearance, $\mathrm{pH}$ analysis, viscosity, spreadability, drug content and in vitro drug release and accelerated stability studies are performed for the efficacy of the formulation.

\section{METHODS}

\section{Formulation of Glucosamine Loaded Solid Lipid} Microparticles ( $G$-SL M)

The melt dispersion technique was used to encapsulate glucosamine into solid lipid microparticles (G-SLM). In the case of the $\mathrm{O} / \mathrm{W}$ precursor, the drug was dispersed into the molten lipid phase, which was emulsified with a hot aqueous surfactant solution with continuous agitation using high speed homogenizer. Later, the emulsion temperature was maintained to the same temperature as the melted lipidic phase. Lipid micro emulsion was then solidified by keeping it on the ice bath to produce lipid microparticles. The obtained GS-SLM was centrifuged at $10,000 \mathrm{rpm}$ for $15 \mathrm{~min}$ to isolate the solid lipid microparticles from the dispersion and dried at desiccator for further analysis. As per the Table-1, we have tested various formulation parameters to optimize the GS loaded solid lipid microparticles to achieve desired particle size $(50-100 \mu \mathrm{m})$ and better encapsulation efficiency $(\geq 75$ $\%)$.

\section{Characterization of Solid Liquid Microparticle}

Measurement of Particle Size and Morphological Character of GS-SLM

The particle size and the morphological appearance of the GSSLM was performed by using scanning electron microscopy (SEM).

\section{Measurement of Zeta Potential of SLM}

Zeta potential of 20 formulations of GS-SLM were measured by photon correlation spectroscopy.

\section{Entrapment Efficiency (EE) of Microparticles}

About $1 \mathrm{~mL}$ of the methanolic solution was prepared and the absorbance of the solution was measured using UV - visible spectrophotometer (Shimadzu, Japan) at $240 \mathrm{~nm}$. The entrapment efficiency was calculated as per the formula.

\section{X-Ray Diffraction (XRD) Analysis}

The $\mathrm{x}$-ray diffraction analysis of the drug, cetyl alcohol and the microparticle formulation by using the $\mathrm{x}$-ray diffract meter (Rigaku Ultima IV, Japan) was done to identify the crystallinity of the substances.

\section{In Vitro Release Studies of GS-SLM}

Modified Franz diffusion cell is used for performing the in vitro drug release and analysed by UV spectrophotometrically at $240 \mathrm{~nm} .^{5}$ 


\begin{tabular}{|c|c|c|c|c|c|c|c|}
\hline \multirow{2}{*}{ Batch Code } & \multicolumn{2}{|c|}{ Lipid (g) } & \multirow{2}{*}{$\begin{array}{c}\text { Drug (g) } \\
\text { (Glucosamine) }\end{array}$} & \multicolumn{3}{|c|}{ Surfactant (\% w / v) } & \multirow{2}{*}{ Homogenizing Speed (rpm) } \\
\hline & Tristearin & Cetyl Alcohol & & PVA & Gelatin & PEG-6000 & \\
\hline 1 & 100 & - & 100 & $1 \% \mathrm{w} / \mathrm{v}$ & - & - & 500 \\
\hline 2 & 200 & - & 100 & $1 \% \mathrm{w} / \mathrm{v}$ & - & - & 500 \\
\hline 3 & 300 & - & 100 & $1 \% \mathrm{w} / \mathrm{v}$ & - & - & 500 \\
\hline 4 & 400 & - & 100 & $1 \% \mathrm{w} / \mathrm{v}$ & - & - & 500 \\
\hline 5 & 500 & - & 100 & $1 \% \mathrm{w} / \mathrm{v}$ & - & - & 500 \\
\hline 6 & - & 100 & 100 & $1 \% \mathrm{w} / \mathrm{v}$ & - & - & 500 \\
\hline 7 & - & 200 & 100 & $1 \% \mathrm{w} / \mathrm{v}$ & - & - & 500 \\
\hline 8 & - & 300 & 100 & $1 \% \mathrm{w} / \mathrm{v}$ & - & - & 500 \\
\hline 9 & - & 400 & 100 & $1 \% \mathrm{w} / \mathrm{v}$ & - & - & 500 \\
\hline 10 & - & 500 & 100 & $1 \% \mathrm{w} / \mathrm{v}$ & - & - & 500 \\
\hline 11 & - & 600 & 100 & $1 \% \mathrm{w} / \mathrm{v}$ & - & - & 500 \\
\hline 12 & - & 500 & 100 & $2 \% \mathrm{w} / \mathrm{v}$ & - & - & 500 \\
\hline 13 & - & 500 & 100 & $3 \% \mathrm{w} / \mathrm{v}$ & - & - & 500 \\
\hline 14 & - & 500 & 100 & - & $1 \% \mathrm{w} / \mathrm{v}$ & - & 500 \\
\hline 15 & - & 500 & 100 & - & $2 \% \mathrm{w} / \mathrm{v}$ & - & 500 \\
\hline 16 & - & 500 & 100 & - & - & $1 \% \mathrm{w} / \mathrm{v}$ & 500 \\
\hline 17 & - & 500 & 100 & - & - & $2 \% \mathrm{w} / \mathrm{v}$ & 500 \\
\hline 18 & - & 500 & 100 & $2 \% \mathrm{w} / \mathrm{v}$ & - & - & 1000 \\
\hline 19 & - & 500 & 100 & $2 \% \mathrm{w} / \mathrm{v}$ & - & - & 1500 \\
\hline 20 & - & 500 & 100 & $2 \% \mathrm{w} / \mathrm{v}$ & - & - & 2000 \\
\hline
\end{tabular}

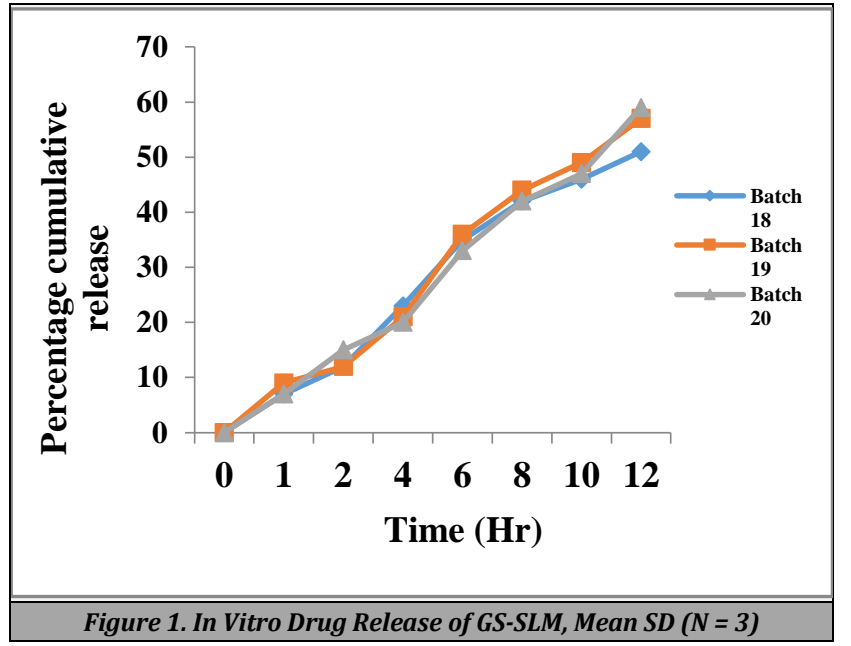

\section{Statistical Analysis}

Of the batches, 18, 19 and 20 of increasing homogenizing speed of 1000, 1500 and $2000 \mathrm{rpm}$ were found to be efficient. So, the batch 18 was found to be the optimised formulation which was further taken for incorporating the Carbopol. The efficient encapsulated glucosamine solid lipid microparticle batch 18 showed constant percentage cumulative release within short period of time.

\section{RESULTS}

The batch code, particle size, encapsulation efficiency and the zeta potential is given in table- 1 . From the table-1, the batches 18,19 and 20 showed the small particle size $(86 \pm 5 \mu \mathrm{m})$ which was suitable for the efficient delivery of solid lipid microparticle (SLM). The encapsulation efficiency was high in case of batch 12 but the particle size was not preferred. Hence from the three batches which showed the suitable particle size but in it the batch 18 showed the better encapsulation efficiency $(81.74 \pm 4.5)$ and has the zeta potential of $(29 \pm 1)$. Also, the batch 18 showed the high percentage cumulative release of glucosamine (Figure 1). Thus, the formulation batch
18 proved to be the efficient formulation as a solid lipid glucosamine microparticle (SLM).

\begin{tabular}{|ccc|c|}
\hline $\begin{array}{c}\text { Batch } \\
\text { Code }\end{array}$ & Particle Size & $\begin{array}{c}\text { Encapsulation } \\
\text { Efficiency }\end{array}$ & Zeta Potential (mV) \\
1 & $418 \pm 2 \mu \mathrm{m}$ & $18.51 \pm 2.5$ & $-17 \pm 2$ \\
2 & $374 \pm 9 \mu \mathrm{m}$ & $21.73 \pm 3.3$ & $-19 \pm 4$ \\
3 & $358 \pm 17 \mu \mathrm{m}$ & $32.17 \pm 1.4$ & $-19 \pm 1$ \\
4 & $342 \pm 8 \mu \mathrm{m}$ & $38.33 \pm 1.9$ & $-18 \pm 1$ \\
5 & $311 \pm 15 \mu \mathrm{m}$ & $43.75 \pm 0.6$ & $-21 \pm 3$ \\
6 & $367 \pm 17 \mu \mathrm{m}$ & $27.59 \pm 2.1$ & $-23 \pm 2$ \\
7 & $343 \pm 11 \mu \mathrm{m}$ & $35.03 \pm 0.5$ & $-22 \pm 1$ \\
8 & $310 \pm 22 \mu \mathrm{m}$ & $52.43 \pm 3.5$ & $-25 \pm 5$ \\
9 & $293 \pm 14 \mu \mathrm{m}$ & $58.11 \pm 2.9$ & $-26 \pm 3$ \\
10 & $280 \pm 18 \mu \mathrm{m}$ & $65.79 \pm 1.5$ & $-29 \pm 3$ \\
11 & $247 \pm 9 \mu \mathrm{m}$ & $61.28 \pm 1.9$ & $-27 \pm 1$ \\
12 & $218 \pm 13 \mu \mathrm{m}$ & $85.43 \pm 4.3$ & $-26 \pm 1$ \\
13 & $213 \pm 15 \mu \mathrm{m}$ & $87.94 \pm 3.2$ & $-24 \pm 2$ \\
14 & $487 \pm 8 \mu \mathrm{m}$ & $54.12 \pm 8.1$ & $-21 \pm 5$ \\
15 & $420 \pm 10 \mu \mathrm{m}$ & $63.37 \pm 5.0$ & $-18 \pm 2$ \\
16 & $470 \pm 17 \mu \mathrm{m}$ & $48.41 \pm 3.4$ & $-23 \pm 1$ \\
17 & $413 \pm 23 \mu \mathrm{m}$ & $59.83 \pm 7.2$ & $-23 \pm 3$ \\
18 & $86 \pm 5 \mu \mathrm{m}$ & $81.74 \pm 4.5$ & $-29 \pm 1$ \\
19 & $76 \pm 7 \mu \mathrm{m}$ & $55.05 \pm 5.7$ & $-28 \pm 2$ \\
20 & $71 \pm 3 \mu \mathrm{m}$ & $48.14 \pm 3.9$ & $-29 \pm 4$ \\
\hline Table 2. Characterisation of Particle Size, Encapsulation Efficiency \\
\multicolumn{4}{|c|}{ and Zeta Potential Analysis of GS-SLM } \\
\hline
\end{tabular}

\section{DISCUSSION}

Formulation of Glucosamine Loaded Hydrogel Carbopol resin was dispersed with continuous stirring in water using mechanical stirrer at $500 \mathrm{rpm}$ until uniform dispersion was achieved. Then drug (glucosamine sulphate; 1 $\% \mathrm{w} / \mathrm{v}$ ), permeation enhancer (oleic acid $2 \% \mathrm{w} / \mathrm{v}$ ) and preservative (benzalkonium chloride $0.25 \% \mathrm{w} / \mathrm{v}$ ) was added. After this the components were completely neutralized using triethanolamine (drop-wise addition) to achieve gel consistency. The prepared GS loaded hydrogel formulations were stored at room temperature for $24 \mathrm{~h}$ to stabilize. ${ }^{6}$

\section{Formulation of GS-SLM Loaded Hydrogel}

The optimised batch of glucosamine sulfate loaded hydrogel formulation parameters were used to prepare GS-SLM loaded hydrogel formulation to achieve sustained drug delivery and ease to administration. In this regard, batch of GS-SLM 
suspension had to take directly without isolating the solid microparticles. Carbopol $1 \% \mathrm{w} / \mathrm{v}$ (which was optimised from our previous study) has dispersed into the above dispersion. The dispersion was stirred using mechanical stirrer at 500 rpm until achieve uniform dispersion and then neutralized by using triethanolamine (drop-wise addition) to form gel consistency. Oleic acid ( $2 \% \mathrm{w} / \mathrm{v}$ ), benzalkonium chloride $(0.25 \% \mathrm{w} / \mathrm{v})$ was used as a permeation enhancer and preservative respectively. The prepared GS-SLM loaded hydrogel was stored at room temperature for 24 hours to stabilise.

\section{Characteristics of Glucosamine Solid Lipid Microparticle Hydrogel}

Physical Appearance

The formulations were tested for their homogeneity by visual appearance after the GS-SLM loaded hydrogels have been set in the suitable container. Also, a small quantity of formulation was pressed between the thumb and the index finger, and the consistency of the hydrogel was noticed whether homogeneous or not [Reshmy Rajan 2012].

\section{pH Analysis}

$\mathrm{pH}$ meter is used for determining the $\mathrm{pH}$ analysis of GS-SLM loaded hydrogel at $25 \pm{ }^{0} \mathrm{C}$.

\section{Viscosity}

The viscosity of the GS-SLM loaded hydrogel formulations was determined using Brookfield viscometer with spindle no. 7 at $100 \mathrm{rpm}$ at the temperature of $25^{\circ} \mathrm{C}$ [A. Salomy Monica 2014].

\section{Spreadability}

The spreadability nature of the GS-SLM was expressed in g.cm / sec.

\section{Drug Content Analysis}

The volumetric flask containing $100 \mathrm{ml}$ of methanol and GSSLM loaded hydrogel was taken. The hydrogel was stirred for $1 \mathrm{hr}$. on magnetic stirrer, at $250 \mathrm{rpm}$, to get complete solubility of the drug. The solution was filtered to remove the undissolved particles and analysis of the drug content was done using UV spectroscopical method [Usama Farghaly Aly 2012].

In Vitro Drug Release Analysis of GS-SLM Loaded Hydrogel and GS Loaded Hydrogel

In vitro release GS-SLM loaded hydrogel (batch code: 18 ) and GS loaded hydrogel were performed as per the previously described method and the results were compared to prove which formulation has the ability to produce sustained drug release.

\section{Accelerated Stability Studies}

Stability studies were carried out on GS-SLM loaded hydrogel according to International Conference on Harmonization (ICH) guidelines. The hydrogel was packed tightly in aluminium tube and was subjected to accelerated stability testing for 3 months duration as per ICH norms at a temperature $\left(40 \pm 2^{\circ} \mathrm{C}\right)$ and relative humidity $75 \pm 5 \%$. Samples were taken at every 1-month interval for over a period of 3 months and investigated for the change in physical appearance, $\mathrm{pH}$, viscosity, drug content and zeta potential.

\begin{tabular}{|c|c|c|c|c|}
\hline Test & Initial & $1^{\text {st }}$ Month & $2^{\text {nd }}$ Month & $3^{\text {rd }}$ Month \\
\hline $\begin{array}{c}\text { Physical } \\
\text { appearance }\end{array}$ & White, opaque & White, opaque & White, opaque & White, opaque \\
\hline $\mathrm{Ph}$ & $5.2 \pm 0.43$ & $5.5 \pm 0.12$ & $5.5 \pm 1.19$ & $5.6 \pm 0.18$ \\
\hline Viscosity (cps) & $16225 \pm 4.8$ & $16641 \pm 5.8$ & $16688 \pm 2.1$ & $16701 \pm 1.3$ \\
\hline $\begin{array}{c}\text { Drug content } \\
(\%)\end{array}$ & $99.4 \pm 0.45$ & $98.2 \pm 0.94$ & $97.26 \pm 3.16$ & $97.19 \pm 1.48$ \\
\hline $\begin{array}{l}\text { Zeta potential } \\
(\mathrm{mV})\end{array}$ & $-29 \pm 4.2 \mathrm{mV}$ & $-26.5 \pm 2.5 \mathrm{mV}$ & $-24.3 \pm 8.7 \mathrm{mV}$ & $-23 \pm 6.24 \mathrm{mV}$ \\
\hline \multicolumn{5}{|c|}{$\begin{array}{c}\text { Table 3. Accelerated Stability Analysis of } \\
\text { Optimised Batch of GS-SLM Loaded Hydrogel }\end{array}$} \\
\hline
\end{tabular}

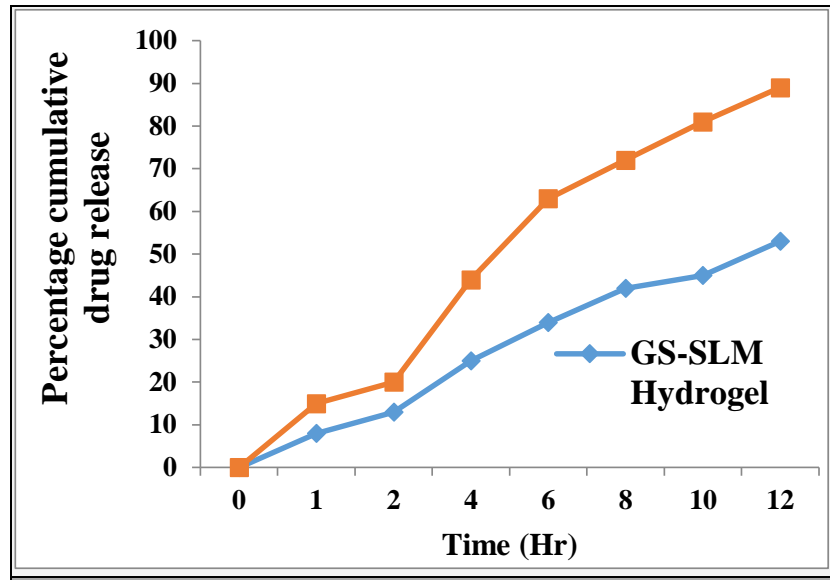

Figure 2. In Vitro Drug Release of GS-SLM Loaded Hydrogel and GS Loaded Hydrogel, Mean SD $(N=3)$

\section{CONCLUSIONS}

On comparing with glucosamine loaded hydrogel, glucosamine solid lipid microparticle-based hydrogel showed smaller particle size, high zeta potential, high encapsulation efficiency and drug release. Various concentrations of lipids and surfactants using different homogenizing speed were tested successfully to optimise the formulation. The optimised formulation exhibited agreeable formulation characteristics such as physical appearance, $\mathrm{pH}$, drug uniformity, spreadability, viscosity, stability and in vitro drug release. The accelerated stability studies also showed that it has no significant change in physicochemical properties during storage. Thus, glucosamine solid lipid microparticle-based hydrogel can be explored as an efficacious novel therapeutic formulation for use in the treatment of osteoarthritis.

Data sharing statement provided by the authors is available with the full text of this article at jemds.com.

Financial or other competing interests: None.

Disclosure forms provided by the authors are available with the full text of this article at jemds.com.

\section{REFERENCES}

[1] Srilekha C, Kumar CP. The study on prevalence and management of osteoarthritis in South India. International Journal of Orthopaedics Sciences 2019;5(4):112-7.

[2] Al-Saadi HM, Pang KL, Ima-Nirwana S, et al. Multifaceted protective role of glucosamine against osteoarthritis: review of its molecular mechanisms. Scientia Pharmaceutica 2019;87(4):34. 
[3] Umeyor CE, Kenechukwu FC, Uronnachi EM, et al. Solid lipid microparticles (SLMS): an effective lipid based technology for controlled drug delivery. Am J Pharm Tech Res 2012;2(6):1-18.

[4] Li J, Mooney DJ. Designing hydrogels for controlled drug delivery. Nat Rev Mater 2016;1(12):16071.

[5] Muthukumar S, Sankar C, Kumaran GA, et al. Formulation and comparative evaluation of etoricoxib loaded osmotic drug delivery systems. Research J Pharm and Tech 2019;12(11):5223-30.

[6] Chellaswamy SK, Natrajan SB. An overview of microparticles loaded hydrogel system for transdermal delivery. Journal of Global Trends in Pharmaceutical Sciences 2020;11(1):7505-13. 